\title{
This Solitude is My Life... A Case Study of Psychological Experiences of Residents of an Old Age Home in Lahore
}

\author{
Faisal Bashir \\ Department of Social Welfare Women Development and Bait Ul Maal, Punjab, Pakistan \\ *Corresponding Author: Faisal Bashir, Department of Social Welfare Women Development and Bait \\ Ul Maal, Punjab, Pakistan
}

Received Date: 19-04-2017

Accepted Date: 29-04-2017

Published Date: 12-06-2017

\section{ABSTRACT}

Old age offers varying [experiences and] meanings in different societies while the aging process is also not uniform for all individuals (Gulzar et al., 2008). Interest in aged care facilities and well-being of its residents is growing and contested in the literature (Akbar et al. 2014; Gulzar et al. 2008; Richards, 2011; Lalan, 2014; Murtaugh 1990; Dubey et al. 2011; Tiwari et al., 2012; Doty, 1992; Vijaykumar, 1995). This paper examines psychological experiences of elderly living in one of a public sector aged care facilities in Lahore, Pakistan. The study was designed with the objective to understand the experience of living in an old age home. The findings provoke questions about the nexus between emotional well-being and mental health issues of the residents. The residents were found vulnerable to become victim of depression and mental issues because of extended emotional loneliness and lack of social support systems.

Keywords: disadvantaged groups, emotional challenges, Pakistan, Old age Homes, older persons.

\section{INTRODUCTION}

According to Pakistan's law, a senior citizen is the one who is aged 60 years and above (Qureshi ?). In developing countries like Pakistan physical effects of aging starts even earlier due to factors including malnourishment, poverty, (Salahuddin \& Jalbani, 2006) and stressful life experiences. The elderly face a wide range of traumatic situations including loneliness, (Salahuddin \& Jalbani, 2006) loss and grief. Apart from other aspects, there is an emotional aspect of aging which entails attitudes, selfperception (Ayranci and Ozdag, 2005; Muhammad et al., 2009) and psychological experiences about self and the world. Old age offers varying [experiences and] meanings in different societies while the aging process is also not uniform for all individuals (Gulzar et al., 2008). Interest in aged care facilities and well- being of its residents is growing and contested in the literature (Akbar et al. 2014; Gulzar et al. 2008; Richards, 2011; Lalan, 2014; Murtaugh 1990; Dubey et al. 2011; Tiwari et al., 2012; Doty, 1992; Vijaykumar, 1995). However, for countries in the global south, this is an emerging field of interest, including Pakistan. According to United Nations (2002) estimate, the population in age group of 60 years and above in Pakistan will increase from 5.8 percent in the year 2000 to 7.3 percent in 2025 and almost double, 12.4 percent in 2050 . The country is not adequately equipped to look after needs of the aging population (Bhasin, 2011) and lacks policy response. Living in Old age homes or aged care facilities is contested and a highlydebated topic in Pakistan given the fact that both culture and religion expects the younger generation to serve their elders in older age. However social milieu is changed, at least for 

in Lahore

those trapped in the vicious circle of poverty. Family structure is changing from joint to nuclear. This transition calls for services for the aged who are no more welcomed in their own families. Public Sector Development Program (PSDP) provide to establish public sector old age homes to cater needs of poor and infirm. (Salahuddin \& Jalbani, 2006). Aged persons, deciding to live in old age home in Pakistan are in a disadvantaged position. They are vulnerable, poor, isolated and generally living without social support systems.

The study was designed with the objective to understand the experience of living in an old age home in Lahore. The specific research question addressed in this paper is; What are the psychological experience of the residents while living in an old age home?

To answer such question qualitative methodology was adopted.

\section{THE METHOD}

The study was conducted using qualitative methodology. Data was collected using semistructured in-depth interviews and observations. The sample was identified purposively. Old people over the age of 60 years and living in an aged care facility for more than a year were the sample population. The residents comprised of both male and female, so the sample also consisted of a gender mix group of 20 elderly living in the old age home; 14 male and 6 female. Male represented more in the group because more male resides in the facility as compared to their female counterparts. Interviews were done in two stages; in first, data relating to demographics and other aspects of the study were collected. In second interview information relating to psychological experiences, and any information not covered in the first interview was covered. Interviews were transcribed and translated in English. Data was analyzed thematically, and all the participants were allocated participant number. The researcher had worked in this home previously and was aware of his insider position as a researcher.

\section{AAFIAT- OLd AGE HOME}

This old age home was established with the objective to provide shelter and home facility to the elderly, with a specific focus on vulnerable and poor. Aafit is a word having broad meanings, however, in this context it can be translated as comfort or wellbeing. The home offers the residential facility to up to 50 individuals. They are provided boarding and lodging facilities in the home. In one room, according to the capacity, two or three elderly are placed. Men and women reside in different wings of the building. The residents follow a structured routine for their day to day activities which ranged from meals to resting times and games to medical appointments. All facilities are provided free of cost.

\section{PSyChological Dimension OF Living in} AN OLd Age HoMe

The residents living in this home and under study were generally poor and vulnerable. Their disadvantaged status in society was driven by factors like inability to work, poor health, lack of income, and family attitude among others. Participants belonged to different areas of the country and had different cultural backgrounds.

The psychological dimension of experience was found to be associated with factors like gender, cultural background, previous financial position, current support system, and extent of social interaction. The participants were generally emotional while talking about the psychological/ emotional dimension of their experience. They were frail in emotional context as well. Extracts from interviews are shared as part of qualitative analysis. At the end of each verbatim gender, participant number and their age are mentioned. The following figure presents different themes identified through analysis. 
This Solitude is My Life... A Case Study of Psychological Experiences of Residents of an Old Age Home in Lahore

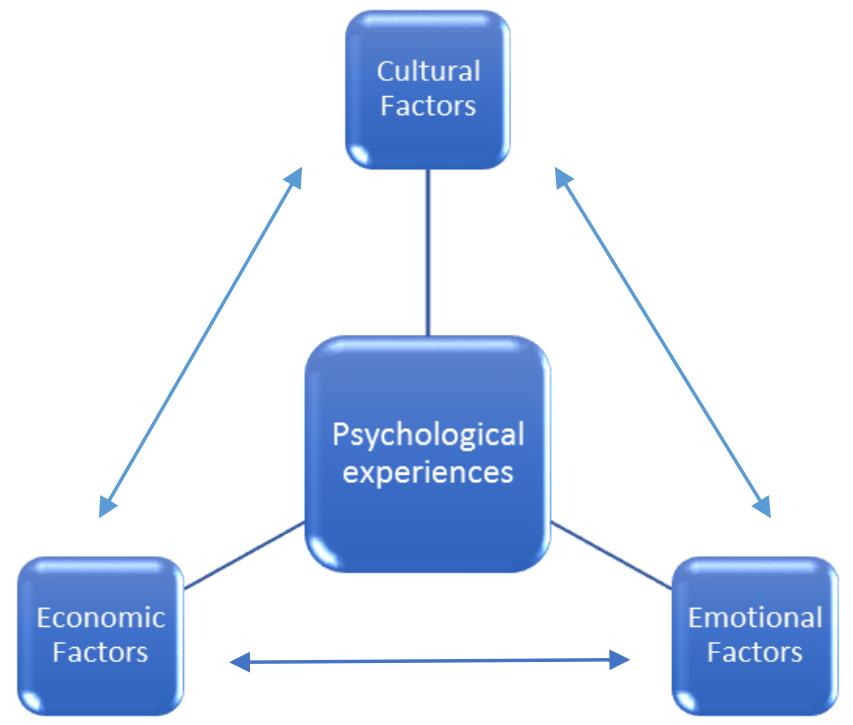

Figure1. Psychological experiences of the Participants and various influencing factors

\section{Cultural Factors}

Although apparently different but in experiences of the elderly two constructs were found to have an association. All of the applicants, both male, and female expressed a varying level of psychological pressure and stress while applying for and getting admission in the facility. Sources of stress appeared to be mainly cultural concerns, availability of vacancies and pressure.

All participants highlighted cultural concerns a source of their stress in one way or another. For men, psychological factors were comparatively less intense in a cultural sense, as compared to women. Participant 1 said something which expressed not only her but of many others agony;

I was so upset, at one hand I had no other option then; to leave home. At other hand, I had strong concerns... really strong concerns. You know in the society, it is such a disgrace if your son cannot look after you in your older age. I did not want this disgrace for myself or my son.' (P1, female, 68)
In that particular culture, children and especially 'the son' is responsible for taking care of the elders. People generally rely on next generation for their look after because they become economically inactive and mostly have spent their earnings. The idea is not only embedded in culture but also religious belief system of the society. The act of sending parents to an old age home is not socially welcomed idea because of the said reasons and associates feeling of shame for the elderly.
'My son and daughter have their own problems, so I cannot stay with them. Such a shame-I am disappointed and distressed! I still feel concerned about what people say about me living in an old age home.' $P 8$, female, 62

The opinion of friends, relatives or community had significance for P4. Since she belonged to thick knit community where everyone knows other person and his life, it concerned her what people will say. In general, it is not a norm to send parents to old age homes, and it becomes even more problematic if the parent going to the facility is a mother. Children are expected to serve parent by all standards; social, cultural, and religious. 
This Solitude is My Life... A Case Study of Psychological Experiences of Residents of an Old Age Home in Lahore

Most of them further explained another dimension of their emotional and psychological experience that is a feeling of failure.

\section{'I feel I have failed. My whole life I was looking after my both sons. I did everything to provide for them. But at the end, they have attained good social status, but I am nowhere, I am abandoned. They don't have even a bed for me. I don't need a lot.'(P9, Male, 70)}

Again, this narrative also highlights cultural perspective. Parents, in Pakistani culture, earn and support their children until they complete their education and in some instances, get married. And as previously mentioned rely on coming generation to look after and care for them in old age. P9's sentiment was not a rare occurrence in the data. An overwhelming majority related to this emotion.

'You know I am a female, at this stage of my life, I should be with my children. When I die, they should arrange for my funeral, not the home. I don't want to survive on welfare money.' (P13, female, 61)

Women experiences appeared as having more of the negative impacts of living in old age facility due to the social understanding of inappropriateness of living there.

Applicants faced psychological pressure while applying to the facility due to uncertainty since there is limited space in the old age home. All applicants shared this stress. They were not certain if they will be able to secure a spot at the facility. Females expressed a more sympathetic attitude of the in-charge of the home who was deciding authority in contrast to males.

\section{Economic Factors}

Financial ability was one of the dimensions of their psychological experience. Almost all of the applicants talked about having no money to spend. They mentioned that on various occasions like Eidi and other festivals they receive some money as a gift. At sometimes some philanthropist visits and distribute money among them. Apart from these, they do not mostly have money to spend. It was a stronger concern for males as in the comparison of females. Because women are mostly economically dependent on a male in the family, which can be a father, brother, husband, or son. The majority of the women, under study, had never been employed. However, all the men in the cohort had been earning in professions like a laborer, a street hawker, rickshaw/taxi driver, butler, and spiritual healer. In Pakistan, retirement age is 60 years, and after that time there are limited employment opportunities left for such older persons.

$$
\begin{aligned}
& \text { 'Well you know sometimes you } \\
& \text { want to go outside the institute, } \\
& \text { you cannot be confined. } \\
& \text { However, you don't have money } \\
& \text { for fare or to buy even a petty } \\
& \text { thing like biscuits. I feel } \\
& \text { disempowered.' (P10, male, 68) }
\end{aligned}
$$

As mentioned in the introduction, the majority of the elderly live in poverty or are vulnerable to enter in the trap of poverty. The impact of poverty is compounded by the emotional stress an elderly face because of lack of financial sources. The institution is already government funded and free of cost so it cannot provide some living allowance to its residents. Female participants also mentioned that although needs are fulfilled through the home, however, they cannot buy anything if they need. The poverty remains almost same except that they get food and shelter.

\section{Emotional Factors}

Loneliness and isolation are identified in several studies as a problem of aged people. In this case, loneliness had become even more complex 
This Solitude is My Life... A Case Study of Psychological Experiences of Residents of an Old Age Home in Lahore

because these senior citizens were living in old age home away from their homes. Most of them stated that feeling of loneliness had been aggravated since they have moved to the home. On the contrary, three participants felt less lonely after moving.

One of the participants aged 71 , male, shared that he had tried suicide because he was fed up with a lonely life. Loneliness was explained in various perspectives, P11 explained all the aspects of his narrative;

'I believe it is lonelier here, at
home I had my grandchildren,
and children of neighbors too.
But here I never see a child.
Back home I had my friends in
the community; we have lived
together since ever. In the
evening, we used to sit together
and chat endlessly, but here it is
different. Though I have some
friends but I don't feel
connected here. Everyone
prefers to live in his ownworld.'
(P11, male, 71)

In the home, older people mostly have the company of little ones, and that provides an informal care for both age groups. However, in old age home, the only people they intermingle with are the aged persons like them. People miss their own old friends. Lack of social support networks in such homes also make older people feel more lonely. Although they make friends, but the sense of connectedness lacks because they were not old friends.

Participant 15 explained another aspect;

Now I understood why they say that man is born alone. When I was able-bodied, I had the whole world around me. Now I need company, and no one is here. Not even my very dear and close ones.' (P15, male, 66)
P6 further added;

'This solitude is my life now.

That time is gone when I was young and had goals. Sometimes I feel my previous life was a dream. I have no goal no aim to live I am just waiting for the final day. I have no purpose of life.' (P6, male, 62)

Feelings of loneliness are not only nested in the feeling of being alone, or being away from own blood relations; these were also deeply rooted in the feeling of lack of purpose in life. In the past they had busy, full lives but now it is opposite situation. No aim for life and passing days while waiting for destiny. A sense of depression was found in most accounts. Their accounts also reflect not only isolation and loneliness but also a strong feeling of neglect by their families.

\section{CONCLUSION}

Culture and norms of the society do not appreciate such facilities however changing pattern of the society has shown increased demand for such homes. There is a clear shift from the joint family system, where family played the role of many social institutions, to a nuclear family system where specialized services in the society are required. Their experiences are complex and are strongly impacted by factors like cultural perspective, the attitude of family, financial wellbeing. The study shows that this significant caveat needs the attention of the society as it is under-researched area in Pakistan. The society is in a transitional phase, moving from joint family system to the nuclear family system. This transition has impacted the aging population negatively. They are also in the transition phase; these elderly people had evidenced a different culture and family system in which senior citizens were the responsibility of 'the family'. However, for them the situation is changed, nuclear family norm increased, and they are sent to old age homes, which was a major dilemma for them. Their 
This Solitude is My Life... A Case Study of Psychological Experiences of Residents of an Old Age Home in Lahore

psychological and emotional experiences are largely related to and impacted by this transition in the society and change in the family system. there are other contributing factors as well like aged persons do not have economic opportunities, so they cannot work as active members of the society and lack financial capability. Keeping in view needs of changing time extended and modern aged care facilities are also required with an effort to de-stigmatize them.

\section{ACKNOWLEDGEMENT}

The author would like to thank all the participants for their participation in this research. Many thanks to anonymous reviewers for their feedback.

\section{REFERENCES}

[1] Akbar, s., Tiwari, S. C., Tripathi, R. K., Kumar, A., Pandey, N. M. (2012). Reasons for Living of Elderly to In Old Age Homes: An Exploratory Study. The International Journal of Indian Psychology. Volume 2, Issue 1.doi: 10.4103/0019-5545.99533

[2] Ali, S.M., \& Kiani, M. F. K. (2003). MIMAP technical paper series no. 18 Ageing and Poverty in Pakistan. Pakistan Institute of Development Economics

[3] Ayranci, U. and N. Ozdag, Old Age and its Related Problems Considered from An Elderly Perspective in A Group Of Turkish Elderly, International J. Geriatrics, and Gerontology, 2005. 5: 22-24

[4] Bhasin, S., Gupta, N., \& Sharma, N. (2011). A Study of Elderly Living in Old Age Home and Within Family Set-up in Jammu Aruna Dubey , Stud Home Com Sci, 5(2): 93-98

[5] Chaudhury, R.H. 2004. Aging in Nepal. Asian Pacific Population Journal Vol. 19, No.1.)

[6] Gulzar, F., Zafar, M. I., Ahmad, A., \& Ali, T, (2008). Socio-economic problems of senior citizens and their Adjustment in Punjab, Pakistan Pak. J. Agri. Sci., Vol. 45(1), 2008
[7] Itrat, A., Taqai, A. M., Qazi, F., \& Qidwai, W. (2007). Family systems: perceptions of elderly patients and their attendents presenting at a university hospital in Karachi, Pakistan. Journal of Pakistan Medical Association, 57(2), 106109.

[8] Jalal, S. \& Younas, M. Z. (2012). Aging and elderly in Pakistan. Ageing Int DOI 10.1007/s12126-012-9153-4

[9] Lalan, Y. (2014). A sociological study of Old persons residing in an Old age Home of Delhi, India. International Research Journal of Social Sciences Vol. 3(4), 21-23

[10] Muhammad, N., Jan, M. A., Shah, M., \& Ahmad, Z. (2009). Old Age People: A SocioEconomic View of their Problems in Peshawar City, Pakistan Pakistan Journal of life and social science. 7(2): 126-130

[11] Murtaugh CM, Kemper P, Spillman BC. The risk of nursing home use in later life. Med Care. 1990; 28:952-62. [PubMed]

[12] Qureshi, K. Ageing: Gender, Social class and Health in Pakistan, Kaveri http://cppg.fccollege. edu.pk/ageing-gender-social-class-and-healthin-pakistan/

[13] Ramashala, M. F. (2001) Living Arrangements, Poverty and the Health of Older Persons in Africa. In Living Arrangements of Older Persons: Population Bulletin of the United Nations, Special Issue Nos. 42/43, p. 365.

[14] Richards, S. (2011). The experience of older people permanently relocating from their home in the community to a long-term care facility: a systematic review. Masters Thesis. The university of Adelid.

[15] The Khyber Pakhtunkhwa Senior Citizens Act, 2014. http://kp.gov.pk/uploads/2016/02/6._Sen ior_Citizens_Act,_2014_.pdf

[16] Saniya R. Sabzwari \& Gohar Azhar. (2012)Ageing in Pakistan-A New Challenge. Aging Int. Springer. DOI 10.1007/s12126-0109082-Z 
This Solitude is My Life... A Case Study of Psychological Experiences of Residents of an Old Age Home in Lahore

[17] Sarfraz, S. F., \& Riaz, S. (2015) Problems Faced by Senior Citizen in Contemporary Society: Findings from the Household Survey in Karachi-Pakistan International Journal of Research in Humanities and Social Studies Volume 2, Issue 11.

[18] United Nations (2002) World Population Ageing 1950-2050. New York: Economic and Social Affairs, Population Division.

[19] Salahuddin, K. \& Jalbani, A.A. (2006). Senior Citizens: A Case Study of Pakistan. Journal of Independent Studies and Research (JISR) Volume 4, Number 2, July 2006

\section{AUTHOR'S BIOGRAPHY}

Mr. Faisal Bashir, has 14 years of postqualification experience of working with international organizations, national level NGOs and government departments. He has worked with Bunyad Literacy Community Council on a project of UNICEF. He has also worked with the department of Social Welfare Women Development and Bait Ul Maal in different capacities and at various locations. His areas of interest include gerontology, human rights, social welfare, community development, and criminology.

Citation: Faisal, Bashir. "This Solitude Is My Life... A Case Study of Psychological Experiences of Residents of an Old Age Home in Lahore." International Journal of Research in Humanities And Social Studies, vol 4, no. 4, 2017, pp. 17-21.

Copyright: (C) 2017 Faisal, Bashir. This is an open-access article distributed under the terms of the Creative Commons Attribution License, which permits unrestricted use, distribution, and reproduction in any medium, provided the original author and source are credited. 